\title{
O ENSINO DE HISTÓRIA DA ENFERMAGEM NOS CURSOS DE GRADUAÇÃO DE SANTA CATARINA
}

\author{
NURSING HISTORY EDUCATION ON GRADUATION COURSES IN SANTA CATARINA
}

Maria Itayra C. de S. Padilha 1

Resumo Partindo da idéia de que o ensino da história da enfermagem é fundamental para a formação dos alunos do curso de graduação e de que a forma como se ministra o seu conteúdo proporciona ou não a aderência a este conhecimento, esta pesquisa pretende estabelecer uma rede de contatos com todas as escolas de enfermagem de Santa Catarina para traçar um diagnóstico do ensino de história da enfermagem. Este poderá subsidiar a criação de uma política para nortear a reformulação curricular da disciplina, face às necessidades do Estado. A metodologia é qualitativa e a coleta de dados inicial identificou, a partir de 15 escolas de enfermagem do Estado, o modus operandi do desenvolvimento da disciplina ao longo do curso. Uma análise inicial indica que as estratégias educacionais e curriculares são variadas, havendo interfaces entre elas. Percebe-se um avanço relativo à carga horária e às estratégias de ensino-aprendizagem, porém a inserção do conteúdo em questão ainda carece de reflexão coletiva sobre a sua importância no currículo dos cursos ${ }^{2}$.

Palavras-chave ensino de enfermagem; história da enfermagem; graduação em enfermagem; currículo.

\begin{abstract}
Concerning to the idea that the nursing history education is fundamental to the development of students of graduation course and that the way this instruction is given determines if its content provides or not the adherence to this information, this research aims to establish a network with all Nursing Schools of Santa Catarina to determine a education diagnosis of nursing history education. This may be a subsidy for a policy creation to guide the curricular reformulation of this subject, in view of the State needs. The methodology is qualitative and the initial data collection identified, from 15 nursing schools of the State, the modus operandi of the subject development along the course. An initial analysis indicates that the educational and curricular strategies are varied, and there are interfaces between them. We note an advance related to the grade hours and to learning-education strategies, however the insertion of said content still needs a collective reflection about its importance on the courses curriculum.
\end{abstract}

Key words nursing education; nursing history; nursing graduation; curriculum. 


\section{Considerações iniciais}

Geralmente a construção de uma história caracteriza-se por ser uma escolha, decorrente de algum tipo de informação e boa dose de motivação por parte do historiador. Esta construção depende basicamente de alguns vestígios encontrados acerca do homem. Em geral, quando os documentos são abundantes, o historiador tem a possibilidade de fazer escolhas, colocar em evidência aquilo que considerar importante e não registrar o que lhe parecer inexpressivo. Sobretudo porque o historiador cria seus materiais, ou, se quiser, recria-os: o historiador não vagueia ao acaso pelo passado como um viajante em busca de achados, mas parte com uma intenção precisa, um problema a resolver, uma hipótese de trabalho a verificar (Febvre, 1989). O trabalho historiográfico situa-se invariavelmente na confluência entre o tempo do objeto investigado e o tempo do sujeito investigador. Reconhecer este olhar datado leva-nos a buscar compreender os condicionamentos e obstáculos que, pela ameaça do anacronismo, podem vir a comprometer o rigor da pesquisa. Por outro lado, compreender o que uma época perguntou a respeito da outra conduz à possibilidade de maior familiaridade com ambas (Boto, 1994).

Já é possível falar de uma história da enfermagem, que percorreu e se deteve em várias fases e compreende produções de maior ou menor peso. Como continuam sendo elaborados artigos, livros, teses e dissertações referentes à sua evolução, o resultado é um quadro bastante heterogêneo. A heterogeneidade não se refere apenas à postura teórica dos trabalhos. Referese aos objetos de pesquisa, às abordagens críticas ou descritivas, às influências predominantes da bibliografia americana ou européia. Como ocorre com quase todos os 'objetos novos' de estudo, a história da enfermagem passa por diversos tipos de abordagem (Lusk, 1997).

A história da enfermagem se confunde com a história das mulheres, que usufruiu e contribuiu para as transformações da História Nova, que alterou o conceito de documentação (pelo valor da história oral), que, por sua vez, diversificou os objetos de estudo (os uniformes, as relações de poder, a identidade profissional, o cuidado, o masculino e o feminino, o processo de trabalho) que seriam foco de interesse historiográfico. A história serve para elucidar o contexto vivido e fornecer os significados desse contexto. Assim, o conhecimento histórico da enfermagem fornece os significados para a cultura da enfermagem (Padilha e Borenstein, 2000). O conhecimento das correntes socioeconômicas, culturais e políticas que influenciaram o longo percurso da história sobre a prática dos cuidados possibilita que as enfermeiras possam libertar-se de heranças passadas. O estudo da história da enfermagem proporciona um maior sentimento de identidade profissional $^{3}$ (Church, 1993, p. 2, tradução do autor). Na verdade, à medida que se 
conhece a história de uma profissão, como, em nosso caso, a enfermagem, é que se percebe quanto e como esta profissão não é inseparável de outras atividades da vida, do mundo da saúde e de seus compromissos sociais. É com este olhar que a história nos oferece a possibilidade de delinear e identificar quem são, o que pensam, o que sentem, como agem e, ainda, que perspectivas têm as enfermeiras sobre o que elas serão no decorrer de sua caminhada enquanto categoria profissional.

A história social pressupõe uma estreita relação entre posições estruturais, interesses sociais e formas de consciência, que ocultam a oposição entre a realidade e a consciência. Assim,

“(...) desde o começo (tratando da história das mulheres que se assemelha e confunde com a história da enfermagem), ligou seu projeto a uma crítica de seus pressupostos, para estar sempre consciente das tensões que atravessam o trabalho e lhe dão o caráter sempre inacabado, sempre aberto a esclarecimentos, perspectivas e interrogações, não só a outras verificações, mas sobretudo a tensões entre a narração cronológica, com seus efeitos de causalidade implícita e vazios de explicações; entre a continuidade da descrição e a descontinuidade dos dados e índices, entre fatos descobertos e sua reconstituição criadora, entre a tentativa de explicação racional e a parte do imprevisto na história; entre a preocupação de expor seus pressupostos e a aspiração de honestidade cientifica" (Varikas, 1991, p. 63).

Percebe-se que desenvolver a pesquisa histórica para construir a memória da enfermagem e analisar criticamente a história das enfermeiras e da enfermagem é um desafio a ser enfrentado cada vez mais intensamente. Para tanto, o registro sistematizado da história da enfermagem em suas diversas faces e fases, nas diferentes regiões do mundo, poderá ser um exercício de autoconhecimento dos enfermeiros, com conseqüente explicação de sua identidade enquanto grupo profissional (Padilha e Borenstein, 2000). E o reconhecimento por parte da sociedade possivelmente virá através do desempenho dos profissionais da enfermagem, sendo que este ainda é um outro desafio a ser enfrentado.

Os significados da profissão enfermagem influenciam sobremaneira a compreensão desta como conceito. Suas representações vêm sendo desconstruídas especialmente pelos estudos desenvolvidos nos últimos 15 anos, sendo substituídas por uma visão mais coerente e mais próxima da realidade, ou seja, a enfermagem como uma profissão que apresenta peculiaridades no cuidar do outro.

Para além das alterações provocadas pela exploração de novas fontes, novas metodologias e novas alianças interdisciplinares, o que sofreu modificações profundas foi a maneira de se considerar os mais incisivos 
vetores históricos: “(...) por um lado, renovou-se o modo de conceptualizar categorias como o espaço, o tempo, a causalidade, a subjetividade, os acontecimentos", por outro, assistiu-se ao surto de "outras histórias" que, de certo modo, desautorizaram a idéia de uma "história universal, só branca, só masculina, sobretudo européia e ocidental" (Di Cori, 1999, p. 31).

O presente estudo está vinculado ao Grupo de Estudos da História do Conhecimento da Enfermagem (GEHCE) e tem por objetivo final traçar um diagnóstico do ensino de história da enfermagem em Santa Catarina, o qual poderá subsidiar a criação de uma política que possa nortear a reformulação curricular da disciplina, face às necessidades daquele estado.

\section{O ensino da história da enfermagem}

O ensino da história da enfermagem no Brasil acontece desde a criação, em 1923, da Escola de Enfermeiras do Departamento Nacional de Saúde Pública (DNSP), atual Escola de Enfermagem Anna Nery. Ao analisarmos os instrumentos legais norteadores da formação da enfermeira, estes já colocavam a necessidade das Bases Históricas, Éticas e Sociais da Arte de Enfermeira ${ }^{4}$ (MS, 1974, p. 65).

Do mesmo modo, a nova ordem estabelecida na formação da enfermeira, em 1949, preservou o ensino de história da enfermagem ${ }^{5}$ (MS, 1974, p. 252). Já em 1962, ao ser fixado o currículo mínimo do curso de enfermagem, agregou-se o estudo da ética à história da enfermagem ${ }^{6}$ (MS, 1974, p. 252). Uma década depois, outra mudança curricular determinou a introdução do exercício de enfermagem, incluindo deontologia médica e legislação profissional, diminuindo o componente relativo à História da Enfermagem ${ }^{7}$ (MS, 1974, p. 723). Mais recentemente, a Portaria Ministerial $n^{\circ} 1.721 / 94$ revitalizou a matéria História da Enfermagem, inserida na área temática Fundamentos de Enfermagem ${ }^{8}$ (MEC, 1994).

Sem dúvida, as mudanças ocorridas nas esferas educacional, política e ideológica marcaram o desenvolvimento do ensino de enfermagem como um todo, assim como o de história da enfermagem (Nogueira, 2000). Os documentos indicam que a estrutura curricular desta disciplina ao longo do tempo sofreu algumas ampliações, mas também algum esvaziamento, na medida em que foram acrescidos conteúdos relativos à ética e legislação profissional, sem a correspondente ampliação da carga horária.

Dentre os estudos que tratam do ensino da história da enfermagem nos currículos de graduação no Brasil, destacamos o de Glete de Alcântara (1966), que analisa o ensino da ética e da história da enfermagem, buscando o consenso entre as duas, considerando-se que, à época, eram ministradas 
em conjunto, porém como disciplinas separadas. Na ocasião, a autora afirmou a respeito do ensino da história que:

“(...) inserida como está na história dos acontecimentos humanos, seus objetivos, sob certos aspectos, são comuns aos da história universal, ou seja, conseguir que os estudantes conheçam e apreciem nossa herança cultural para melhor entenderem a sociedade em que vivem" (Alcântara, 1966, p. 397).

Vitória Secaf também apresenta sua experiência com o ensino da história da enfermagem na Escola de Enfermagem da Universidade de São Paulo (EE-USP) e conclui que

“(...) o ensino de história da enfermagem e obstetrícia deveria ser realizado de tal forma que permita desenvolver nos alunos a curiosidade intelectual, o interesse e a atenção para os valores contidos na disciplina. E além dos conhecimentos específicos, promova o desenvolvimento de atitudes e valores sócio-profissionais" (Secaf, 1977, p. 81).

Em 2000, o Núcleo de Pesquisa de Estudos Históricos da Enfermagem Brasileira (NUPHEBRAS) da Escola de Enfermagem Anna Nery, da UFRJ, realizou o $1^{\circ}$ Colóquio Latino-Americano de História da Enfermagem, no qual foram apresentadas várias experiências sobre o ensino de história da enfermagem no Brasil e na América Latina. Nestas, percebem-se algumas estratégias inovadoras de ensino, tais como articulação aos grupos de pesquisa e a disciplinas da pós-graduação e atividades em centro de documentação, o que confere um modo mais construtivista de ensinar e aprender a história da enfermagem ${ }^{9}$.

Na perspectiva americana sobre a inserção da história da enfermagem no currículo, Arlene Keeling se posiciona do seguinte modo:

“(...) incluir a história da enfermagem no currículo nos permitirá educar mais do que 'treinar' nossos estudantes. Assim, nós daremos a eles um senso de identidade profissional, uma habilidade no uso da metodologia de pesquisa e um contexto para avaliar as informações"10 (Keeling, 2005, p. 3, tradução do autor).

O professor de história da enfermagem necessita olhar para o sociólogo, o etnólogo, o economista, o psicólogo, dentre outros, e também metamorfosear a memória coletiva dos homens e obrigar o conjunto das ciências e dos saberes a situar-se em outra direção, conforme outra concepção de mundo e sua evolução. Afinal,

“Ensinar não se esgota no tratamento do objeto ou do conteúdo, superficialmente feito, mas se alonga à produção das condições em que aprender criticamente 
é possível. E essas condições implicam ou exigem a presença de educadores e educandos criadores, instigadores, inquietos, rigorosamente curiosos, humildes e persistentes" (Freire, 1997, p. 29).

Os significados da profissão enfermagem influenciam sobremaneira a compreensão desta como conceito. Isto pode ser evidenciado no discurso de Ethel Parsons, que, ao criar o Serviço de Enfermeiras do DNSP, em 1922, hesitou em utilizar a palavra 'enfermeira' devido à conotação negativa que ela apresentava na época, preferindo o termo nurse, a fim de diferenciar as profissionais formadas sob sua orientação das demais. No entanto, o termo não teve aceitação, prevalecendo formas de denominação que as diferenciavam das demais 'enfermeiras da época', como 'enfermeira de alto padrão', 'de saúde pública' ou, simplesmente, 'diplomadas', que permanecem até hoje (Alcântara, 1966, p. 20).

Desde então, muita coisa mudou, tanto na enfermagem quanto em seus conceitos e significados para a sociedade. Entendemos que, ao ingressarem no curso de graduação em enfermagem, as alunas trazem consigo significados e representações acerca da profissão, que serão modificados ou confirmados ao longo do curso. Muitos significados foram construídos a partir de sua formação familiar e social e orientam o seu agir diante do curso de graduação, isto é, são significados carregados de historicidade que influenciam a escolha e, posteriormente, direcionam a prática profissional (Padilha, 1991).

A percepção das alunas tanto pode ser uma visão romântica da 'dama de branco', ou da 'dama da lâmpada', que serve ao próximo sem esperar recompensa pelo seu trabalho, estando presente 24 horas por dia de forma submissa e abnegada; como da 'dama de vermelho', ou da 'bêbada', que serve ao médico e aos seus próprios interesses. Esta representação vai sendo desconstruída ao longo do curso de graduação e da vida profissional, sendo substituída por uma visão mais coerente e mais próxima da realidade, ou seja, uma visão da enfermagem como uma profissão que tem singularidades no cuidado.

A enfermagem científica moderna está na fase de transição para o paradigma das ciências pós-modernas e exige uma reflexão coletiva na qual enfermeiras e enfermeiros compreendam que a nova conflitualidade das ciências está se dando entre os partidários do cuidado edificante e os partidários do cuidado como técnica, necessitando de uma reflexão global sobre a ciência do período da crise de degenerescência do paradigma das ciências modernas (Santos, 2001).

O que temos percebido ao longo de nossa experiência profissional nesta área, e como responsáveis pela disciplina de história da enfermagem há nove anos, é que existe uma imensa discrepância entre as formas como a disciplina é entendida pelos docentes que a ministram. Alguns utilizam uma 
abordagem tradicional, fundamentada na educação 'bancária' tão criticada por Paulo Freire e outros educadores; e outros procuram uma abordagem mais problematizadora, utilizando técnicas de ensino inovadoras, como vídeos, dinâmicas de grupo, debates, dentre outras, que permitem e incentivam a participação discente.

\section{O ensino de história da enfermagem em Santa Catarina}

Para traçar um diagnóstico do ensino de história da enfermagem em Santa Catarina, o qual subsidiará a criação de uma política que possa nortear a reformulação curricular da disciplina, estamos desenvolvendo desde 2004 o projeto de pesquisa intitulado "A instrumentalização de docentes para o ensino da história da enfermagem nos cursos de graduação do estado de Santa Catarina". Este projeto foi aprovado pelo CNPq e está vinculado ao GEHCE, da UFSC. Para atingir o objetivo, realizamos uma análise preliminar dos planos de ensino referentes ao conteúdo de história da enfermagem, o que possibilitou que traçássemos um panorama do desenvolvimento da disciplina nas escolas. Esta análise propiciou que identificássemos uma desconexão entre os modos como as escolas percebem este ensino em sua estrutura curricular, assim como entre os tipos de conteúdo considerados essenciais. Em 2005, durante o $19^{\circ}$ Fórum Catarinense de Escolas de Enfermagem em Tubarão (SC), realizamos uma oficina com os participantes do encontro, à qual levamos os problemas previamente identificados e trabalhamos questões relativas a como se dá o ensino da história da enfermagem nas instituições e como deveria ser11 (Padilha, 2004).

Neste sentido, avaliamos que o estado de Santa Catarina conta com 20 escolas de enfermagem, distribuídas por diversas regiões. Para proceder à análise da situação do ensino do tema em Santa Catarina, solicitamos às escolas seus planos de ensino relativos à disciplina de história da enfermagem ${ }^{12}$.

O conteúdo de história da enfermagem está presente desde 1969 no currículo dos cursos de enfermagem em Santa Catarina ${ }^{13}$, como disciplina independente ou integrado em outra disciplina ou área temática, como ocorre no currículo atual. É fato que este assunto constou de todas as reformulações legais e continua na ordem do dia.

A carga horária da disciplina varia entre 30 e 60 horas, e o conteúdo a ser ministrado, normalmente, segue a orientação curricular da escola ou departamento ao qual pertence. Além disso, em muitos cursos não existe a disciplina específica de história da enfermagem, mas sim, estudos vinculados à introdução à enfermagem; ética e exercício da enfermagem; fundamentos históricos e éticos da enfermagem; história da enfermagem, legislação e deontologia. Na reforma curricular, o conteúdo relativo a este tema está 
vinculado à área temática fundamentos de enfermagem, o que significa que pode ser oferecida como disciplina ou como inserção de conteúdos ao longo do curso, de acordo com a proposta curricular de cada instituição.

As ementas da disciplina se orientam, via de regra, pelos seguintes elementos: desenvolvimento histórico das práticas de saúde; origem da enfermagem; contextualização do período Florence Nightingale; a enfermagem brasileira; realidade atual e perspectivas da enfermagem em Santa Catarina e no Brasil; legislação do ensino de enfermagem e do exercício profissional e órgãos de classe; áreas de atuação do enfermeiro e perspectivas da enfermagem brasileira; aspectos sociais, políticos e econômicos na prestação do cuidado em saúde.

Os conteúdos seguem uma regra geral, sendo relativos aos temas: evolução da enfermagem ao longo dos séculos no mundo e no Brasil; Florence Nightingale e a enfermagem moderna; entidades associativas na enfermagem; legislação profissional; legislação do ensino de enfermagem; enfermagem em Santa Catarina e suas práticas; o processo e o método da assistência de enfermagem, entre outros.

Normalmente, os conteúdos relativos à história da enfermagem são oferecidos aos alunos nos primeiros períodos do curso, quando ainda não sabem exatamente o significado da profissão enquanto ação, identidade, opção e teorização. Dentre as estratégias de ensino e aprendizagem adotadas, as mais freqüentes são: aula expositiva dialogada, seminário, trabalho individual e em grupo e discussão sistemática dos temas abordados. Acontecem, isoladamente, algumas com dinâmicas mais problematizadoras, como dinâmicas de grupo, exibição de filmes relacionados ao assunto, atividades práticas e apresentações de teatro.

Quanto ao sistema de avaliação, as estratégias mais freqüentes são provas, resenhas, trabalhos e elaboração de textos interpretativos. No item participação, incluem-se presença, pontualidade, habilidades em debates, trabalhos escritos e painéis. No item apresentação de trabalho, consideram-se organização do grupo, domínio do assunto, motivação exercida na classe, recursos didáticos aplicados, objetividade e linguagem utilizada.

\section{Considerações finais}

A relação da profissão com a sociedade é permeada pelos conceitos, preconceitos e estereótipos que se estabeleceram em sua trajetória histórica e que influenciam até hoje a concepção do que é a enfermagem, a que vem e qual o seu significado enquanto profissão da saúde composta de 'gente que cuida de gente'. Em parte, a história da enfermagem, assim como a história das mulheres, continua sendo um campo suplementar. Hoje, tem-se clareza 
sobre a 'historicidade da história', que contribui para o desdobramento dos processos de recuperação da verdade entre o presente e o passado. Acrescentando às contribuições do método biográfico e às técnicas de história oral, Pierre Nora (1993) introduziu a ego-história, como tomada de consciência de que a história que cada um faz é tributária de sua própria história e da relação que teve com a sua época.

Em pesquisa sobre os estudos históricos no Brasil decorrentes dos resultados de teses e dissertações ${ }^{14}$, identificamos apenas 88 estudos que tratavam de temáticas como identidade profissional, institucionalização da enfermagem no Brasil, entidades organizativas, especialidades de enfermagem e estudos sobre a criação das escolas de enfermagem brasileiras. Nestes estudos percebe-se que a partir da década de 1980, acentuaram-se as preocupações das estudiosas de enfermagem com os estudos da profissão numa perspectiva historiográfica, especialmente para compreender a enfermagem como parte de um processo histórico, social, cultural, político, educativo e de gênero (Padilha, 2004).

Entendemos a história da enfermagem, no campo do ensino e pesquisa, ainda em processo de sedimentação e ampliação, cabendo ainda reconhecer as limitações visíveis da produção científica da enfermagem brasileira - em processo de acelerado desenvolvimento - no que se refere aos estudos de natureza sócio-histórica, que possam criar possibilidades de 'reconstrução' dos saberes constituintes dos contextos históricos e culturais específicos, inclusive de um campo de saber e prática como o da enfermagem (Padilha, 2004, 1991).

“A contribuição da história da enfermagem se dá primeiro na formação de uma consciência crítica e reflexiva e de uma atitude intelectual do enfermeiro e depois no que se refere à elaboração de novas formas de percepção e apreciação da realidade social, que possibilitem uma concepção e uma formulação mais elaborada de um projeto profissional concentrado. A prática pedagógica em história da enfermagem, entendida como prática de ensino ou de orientação favorece o desenvolvimento de capacidades de reconstrução de visões do senso comum, pela contextualização do problema e pela análise dos interesses que movem os grupos empenhados no jogo de forças, que determina os rumos da história" (Barreira e Baptista, 2003, p. 705).

A História, para nós, é um imenso campo de possibilidades, em que inúmeros 'agoras' irão questionar momentos, trabalhar perspectivas e investigar pressupostos. A problematização da história é um ponto de partida para entender os desdobramentos que sofreu a enfermagem, e não apenas uma referência com base na historiografia ou nos livros que já foram escritos. A problematização em torno dos desafios e tendências futuros sobre o ensinar, 
aprender e pesquisar a história da enfermagem para todos os níveis é uma possibilidade de reduzir as insuficiências neste campo de estudo e mobilizar docentes, discentes e outros interessados para a importância da história da enfermagem enquanto profissão constitutiva de uma área de saber, estabelecendo a ponte entre passado e presente, para construção do futuro.

\section{Notas}

${ }^{1}$ Professora do Departamento de Enfermagem da Universidade Federal de Santa Catarina (UFSC). Doutora em Enfermagem pela Universidade Federal do Rio de Janeiro (UFRJ). Pesquisadora do CNPq. <padilha@nfr.ufsc.br>.

2 Este artigo foi elaborado a partir do projeto de pesquisa intitulado "A instrumentalização de docentes para o ensino da história da enfermagem nos cursos de graduação do Estado de Santa Catarina", aprovado pelo CNPq e vinculado ao Grupo de Estudos da História do Conhecimento da Enfermagem (GEHCE), da UFSC. A pesquisa encontrase em andamento.

3 "The study of nursing history also provides a sense of professional identity".

4 Decreto $\mathrm{n}^{\circ} 16.300$, de 31 de dezembro de 1923, que aprova o regulamento do Departamento Nacional de Saúde Pública.

${ }^{5}$ Decreto $\mathrm{n}^{\circ} 27.426$, de 14 de novembro de 1949, que aprova o regulamento básico para os cursos de enfermagem e de auxiliar de enfermagem.

6 Parecer no 271, de 19 de outubro de 1962, do Conselho Federal de Educação, que dispõe sobre o currículo mínimo do curso de enfermagem.

${ }^{7}$ Parecer $n^{\circ}$ 163, de 28 de janeiro de 1972, do Conselho Federal de Educação, que dispõe sobre o currículo mínimo dos cursos de enfermagem e obstetrícia, e resolução $\mathrm{n}^{\circ} 4$, de 25 de fevereiro de 1972, do Conselho Federal de Educação, que define o currículo mínimo dos cursos de enfermagem e obstetrícia.

8 Portaria n ${ }^{\circ} 1.721$, de 15 de dezembro de 1994, do Ministério da Educação e Cultura, que estabelece o novo currículo mínimo de graduação em enfermagem.

${ }^{9}$ Entre os textos, foram apresentados os panoramas do ensino da história nas regiões Nordeste e Sul no brasil, no México e no Peru. Também foram feitas reflexões sobre a investigação e a documentação da história da enfermagem dos pontos de vista brasileiro e chileno (Escola Anna Nery Revista de Enfermagem, 2000).

10 " (...) including nursing history into the curriculum will allow us to educate rather than 'train' our students. In so doing, we will give them a sense of professional identity, a useful methodological research skill, and a context for evaluation information". 
11 Em 2006, o $20^{\circ}$ Fórum Catarinense de Escolas de Enfermagem, promovido pela Associação Brasileira de Enfermagem de Santa Catarina (Aben/SC), ocorreu em Blumenau, nos dias 18 e 19 de maio. No dia 19, aconteceu uma segunda oficina, para a continuidade do diálogo com os professores interessados em discutir o ensino da história da enfermagem nas escolas. Naquele momento, pretendemos avaliar os pontos fortes e frágeis, traçar uma política para o desenvolvimento do ensino da história da enfermagem pelas escolas de enfermagem de Santa Catarina e finalizar a pesquisa.

12 Não identificaremos, neste momento, as 15 escolas que atenderam a nossa solicitação, porque elas ainda não assinaram o consentimento livre e esclarecido do uso deste material. Assim, somente apresentaremos os dados, a título de ilustração e para enriquecer discussões posteriores.

$13 \mathrm{O}$ primeiro curso de graduação em enfermagem foi criado em 24 de janeiro de 1969 , na Universidade Federal de Santa Catarina.

14 Foram estudados aproximadamente 2.525 resumos de teses e dissertações produzidas desde a criação de seus primeiros programas (1972) até o ano de 2003, por meio de consulta aos Catálogos de Informações sobre Pesquisas e Pesquisadores em Enfermagem, período 1979 a 2003, que publicam os resumos dos exemplares que compõem o Banco de Teses do Centro de Estudos e Pesquisas em Enfermagem (Cepen/Aben), anterior ao banco atualmente mantido pela Capes.

\section{Referências}

ALCÂNTARA, Glete. 1966. O ensino da ética e da história da enfermagem. Revista Brasileira de Enfermagem, v. 19, n. 4, p. 393-402.

BARREIRA, Ieda; BAPTISTA, Sueli. 2003. O movimento de reconsideração do ensino e da pesquisa em história da enfermagem. Revista Brasileira de Enfermagem, v. 56, n. 6, p. 702-706.

BOTO, Carlota. 1994. Nova história e seus velhos dilemas. Revista USP, n. 23, p. 23-33.

CHURCH, Olga M. 1993. In search of nursing's history. Deans Notes, v. 15, n. 1, p. 1-3.

DI CORI, Pietro. 1999. Insegnare la storia. Traubewn: Torino.

ESCOLA ANNA NERY Revista de Enfermagem. 2000. v. 4, n. 3/3.

FEBVRE, Lucien. 1989. De 1892 a 1933: exame de consciência de uma história e de um historiador. In: Combate pela história. $2^{\mathrm{a}}$ ed. Lisboa: Presença.
FREIRE, Paulo. 1997. Pedagogia da autonomia: saberes necessários à prática educativa. $6^{a}$ ed. São Paulo: Paz e Terra.

KEELING, Arlene. 2005. Nursing History in the curriculum: preparing nurses for the 21 st century. Disponível em: <aahn. org/position.html> . Acesso em: 20 mar. 2006.

LUSK, Brigid. 1997. Historical methodology for nursing research. Journal of Nursing Scholarship, v. 29, n. 4, p. 355-359.

MEC (Ministério da Educação e do Desporto). 1994. Portaria no. 1.721, de 15 de dezembro de 1994. Estabelece o currículo mínimo do Curso de Graduação em Enfermagem.

MS (Ministério da Saúde). 1974. Enfermagem: legislação e assuntos correlatos. $3^{\mathrm{a}}$ ed. Rio de Janeiro: Fundação Serviços de Saúde Pública.

NOGUEIRA, Lidya T. 2000. O ensino de história da enfermagem e o resgate da memória: panorama nos cursos de enfermagem da região Nordeste. Escola 
Anna Nery Revista de Enfermagem, v. 4, n. 3/3, p. 321-332.

NORA, Pierre. 1993. Entre memória e história: a problemática dos lugares. Projeto História, n. 10, p. 7-28.

PADILHA, Maria Itayra C. de S. 1991. O resgate das raízes: a influência da formação familiar e social na escolha e exercício da enfermagem. Revista Brasileira de Enfermagem, v. 44, n. 1, p. 30-35.

1994. A mulher enfermeira nos âmbitos doméstico-familiar e público. Revista Gaúcha de Enfermagem, v. 15, n. $1 / 2$, p. 5-12.

. 2004. A enfermagem em foco: perspectivas no ensinar e aprender a história da profissão. In: $56^{\circ}$ Congresso Brasileiro de Enfermagem, Gramado, RS. Anais.
Natal, RN: Associação Brasileira de Enfermagem (ABEn), p. 125.

2005. O método de pesquisa histórica na enfermagem. Texto \& Contexto Enfermagem, v. 14, n. 4, p. 575-584.

; BORENSTEIN, Miriam S. 2000. O panorama da história da enfermagem na região Sul do Brasil. Escola Anna Nery Revista de Enfermagem, v. 4, n. 3, p. 369-375.

SANTOS, Boaventura S. 2001. Um discurso sobre as ciências. Porto: Afrontamento.

SECAF, Vitória. 1977. Uma experiência no ensino de história da enfermagem. Revista Brasileira de Enfermagem, v. 30, p. 76-81.

VARIKAS, Eleni. 1991. Genre, expérience et subjectivité: a propos du désaccord TillyScott. Passato e Presente, n. 5. p. 24- 36.

Recebido em 15/12/2005

Aprovado em 12/06/2006 